\title{
A Novel Paper on Identification of Maximum Loading Point Using Continuation Power Flow Method
}

\author{
Mr. Yogesh H. Joshi ${ }^{1}$, Mr. Omkar M. Shete ${ }^{2}$, Mr. Vinod Kumar P. More \\ Asst. Prof., Electrical Engineering Department, NBNSSOE, Pune, India ${ }^{1,2,3}$
}

\begin{abstract}
In the wake of the worst power crisis in a decade in India, there is a need to build new generating stations, use alternative sources such as wind, solar, geothermal etc. To improve the power transfer capability, we must operate the system up to its Maximum Loading Point without losing its stability. This paper describes the Continuation Power Flow method which is efficient to find out the critical line outage and can operate the system upto its Maximum Loading Point without any stability problem. The proposed work is analysed using IEEE 30 bus test system. Here, Maximum Loading Point is identified under normal condition and also at different line outage conditions.
\end{abstract}

Keywords: Maximum Loading Point, Continuation Power Flow, Line Outage, Stability.

\section{INTRODUCTION}

The main objective of voltage stability analysis is the computation of the system Maximum Loading Point (MLP). Determining the MLP or Voltage Collapse Point, as well preventing the system from being operated close to the stability limits is very important in power system planning and operation. The MLP is associated to a physical limitation of the power system network for a particular configuration \& load condition. It should not be based on the mathematical limitation of the numerical method. The maximum loading condition can be determined in such a way that the static stability of the system will be maintained not only in normal operation of the system but also in emergency conditions and in case of the occurrence of contingency for atleast one of the components of the system.

Power system contingencies based on the effects of them on Mega Watt Margin (MWM) and MLP is focused in order to analyse the static voltage stability using continuation power flow method [1].Using a continuation power flow method and considering single power plant unit outages in power system, maximum loading point of the system is analysed in [2]. The applications of generator reactive power limit technique to systems in order to determine bifurcation points and voltage stability are discussed in [3]. Fuzzy approach for ranking critical buses in a power system under normal and network contingencies based on line Flow index and voltage profiles at load buses are discussed in [4]. Maximum loadability of a particular load bus in the system is based on the Fast voltage stability index (FVSI) in [5]. Voltage contingency selection and ranking is analysed using neural network in [6]. An algorithm for a fast continuation load flow to determining critical load for a bus with respect to its voltage collapse limit of an interconnected multi-bus power system using the criteria of singularity of load flow jacobian matrix in [7]. This paper presents the Continuation Power Flow (CPF) method to rank critical buses in a power system under normal and network contingencies. The $\mathrm{CPF}$ method can able to trace $\mathrm{P}-\mathrm{V}$ curve starting from a base case until the MLP solving successive power flows for different line outage conditions.

\section{VOLTAGE STABILITY}

Voltage stability is the ability of a power system to maintain steady acceptable voltages at all buses in the system under normal operating conditions and after being subjected to a disturbance. Nowadays, the increase in peak load demand and power transfers between utilities has an important issue on power system voltage stability. Voltage stability believed to be a greater concern in the future because of the need to use the invested capital efficiently, difficulties in supervising a deregulated market and the public opposition to building new transmission lines and power plants. The maximum allowable voltage limit is called stability limit. The stability limit is called as the critical point or MLP. It is defined as the point where the power flow jacobian becomes singular. Voltage stability problem arises when the system is heavily loaded that causes to go beyond limitations of power system. A power system enters a state of voltage instability when a disturbance, increase in load demand or change in system conditions causes a progressive and uncontrollable decline in voltage. The main factor causing instability is the inability of the power system to meet the demand for reactive power. In a power system, we encounter with a many contingencies that may result in overload in some of the lines and bus voltage deviation from their allowed limit, so that the position of the weakest bus may change.

\section{III.CONTINGENCY ANALYSIS AND RANKING}

Contingency Analysis (CA) aims at analysing the system response to large disturbances that may lead to instability and collapse. The system is considered secure if it can withstand each set of credible outages, referred to as contingencies. CA is a computer application that uses a simulated model of the power system, to evaluate the effects, and calculate any overloads, resulting from each 
outage event. CA is used as a study tool for the off-line Now, substitute the equations (8) and (9) in the above analysis of contingency events, and as an on-line tool to equations (6) and (7), then

show operators what would be the effects of future outages. Here the contingency analysis and ranking is done using Continuation Power Flow method for different outage conditions. The line outage with highest rank is identified as the most critical outage and hence a list of critical contingencies can be identified.

\section{IV.CONTINUATION POWER FLOW METHOD}

The jacobian matrix of power flow equations becomes singular at the voltage stability limit, CPF method overcomes this problem. This method finds successive load flow solutions according load scenario. In order to apply continuation method to the power flow problem, the power flow equations must reformulated to include a load parameter $\lambda$. Let $\lambda$ represent the load parameter such that

$$
0 \leq \lambda \leq \lambda_{\text {critical }}
$$

where, $\lambda=0$ corresponds to the base load and $\lambda=\lambda_{\text {critical }}$ corresponds to the critical load. This reformulation can be accomplished by expressing load and generation at a bus as a function of the load parameter $\lambda$. Thus, the general forms of new equations for each bus $i$ are

$$
\begin{aligned}
& \Delta \mathrm{P}_{\mathrm{i}}=\mathrm{P}_{\mathrm{Gi}}-\mathrm{P}_{\mathrm{Li}}-\mathrm{P}_{\mathrm{Ti}}=0 \\
& \Delta \mathrm{Q}_{\mathrm{i}}=\mathrm{Q}_{\mathrm{Gi}}-\mathrm{Q}_{\mathrm{Li}}-\mathrm{Q}_{\mathrm{Ti}}=0
\end{aligned}
$$

where,

$$
\begin{aligned}
& \mathrm{P}_{\mathrm{Ti}}=\sum_{\mathrm{j}=1}^{\mathrm{n}} \mathrm{V}_{\mathrm{i}} \mathrm{V}_{\mathrm{j}} \mathrm{Y}_{\mathrm{ij}} \cos \left(\theta_{\mathrm{ij}}+\delta_{\mathrm{j}}-\delta_{\mathrm{i}}\right) \\
& \mathrm{Q}_{\mathrm{Ti}}=\sum_{\mathrm{j}=1}^{\mathrm{n}} \mathrm{V}_{\mathrm{i}} \mathrm{V}_{\mathrm{j}} \mathrm{Y}_{\mathrm{ij}} \sin \left(\theta_{\mathrm{ij}}+\delta_{\mathrm{j}}-\delta_{\mathrm{i}}\right)
\end{aligned}
$$

where,

$\mathrm{P}_{\mathrm{Gi}}$ :- Real power generation at bus $\mathrm{i}$

$\mathrm{Q}_{\mathrm{Gi}}$ :- Reactive power generation at bus $\mathrm{i}$

$\mathrm{P}_{\mathrm{Li}}$ :- Real power load at bus $\mathrm{i}$

$\mathrm{Q}_{\mathrm{Li}}$ :- Reactive power load at bus $\mathrm{i}$

$\mathrm{P}_{\mathrm{Ti}}$ :- Total injected real power at bus $\mathrm{i}$

$\mathrm{Q}_{\mathrm{Ti}}$ :- Total injected active power at bus $\mathrm{i}$

$\mathrm{V}_{\mathrm{i}} \quad \delta_{\mathrm{i}} / \mathrm{V}_{\mathrm{j}} \quad \delta_{\mathrm{j}}: \not$ are voltages at buses $\mathrm{i}$ and $\mathrm{j}$ respectively

$\mathrm{Y}_{\mathrm{ij}} \angle \theta_{\mathrm{ij}}$ :- is the element of $\mathrm{Y}_{\text {bus }}$ matrix

$\mathrm{n}$ :- Number of buses in the system

To simulate a different load change, the $\mathrm{P}_{\mathrm{Li}}$ and $\mathrm{Q}_{\mathrm{Li}}$ terms must be modified. This can be done by splitting each term into two components. One component will correspond to the original load at bus $\mathrm{i}$ and the other component will represent a load change brought about by a change in the load parameter $\lambda$. Thus,

$$
\begin{aligned}
& P_{L i}=P_{L i 0}+\lambda\left(K_{L i} S_{\Delta \text { base }} \cos \psi_{i}\right) \\
& Q_{L i}=Q_{L i 0}+\lambda\left(K_{L i} S_{\text {Dbase }} \sin \psi_{i}\right)
\end{aligned}
$$

$P_{L i 0}, Q_{L i 0}$ :- are original real and reactive loads respectively at bus $\mathrm{i}$

$\psi_{i}$ :- Constant used to specify the rate of load change at bus $i$ as $\lambda$ changes

$S_{\Delta b a s e}:-$ given quantity of apparent power which is chosen to provide appropriate scaling of $\lambda$. Here,

$$
\begin{aligned}
& S_{\Delta \text { base }} \cos \psi_{i}=P_{L i 0} \\
& S_{\Delta \text { base }} \sin \psi_{i}=Q_{L i 0}
\end{aligned}
$$

$$
\begin{aligned}
& P_{L i}=P_{L i 0}\left(1+\lambda K_{L i}\right) \\
& Q_{L i}=Q_{L i 0}\left(1+\lambda K_{L i}\right)
\end{aligned}
$$

The real power generation term can be modified to

$$
P_{G i 0}=P_{G i 0}\left(1+\lambda K_{G i}\right)
$$

The values of $\mathrm{K}_{\mathrm{Li}}, \mathrm{K}_{\mathrm{Gi}}$, can be uniquely specified for every bus in the system.

where,

$\mathrm{P}_{\mathrm{Gi}}$ :- Real power generation at bus $\mathrm{I}$ in the base case.

$\mathrm{K}_{\mathrm{Gi}}$ :- Constant used to specify the rate of change in generation as $\lambda$ varies.

$\mathrm{P}_{\mathrm{Li} 0}, \mathrm{Q}_{\mathrm{Li} 0}$ :- are real and reactive base loads

$\mathrm{P}_{\mathrm{Li}}, \mathrm{Q}_{\mathrm{Li}}$ :- are the real and reactive loads at bus $\mathrm{i}$ for the current operating point as defined by $\lambda$.

\section{MAXIMUM LOADING POINT IN A POWER SYSTEM}

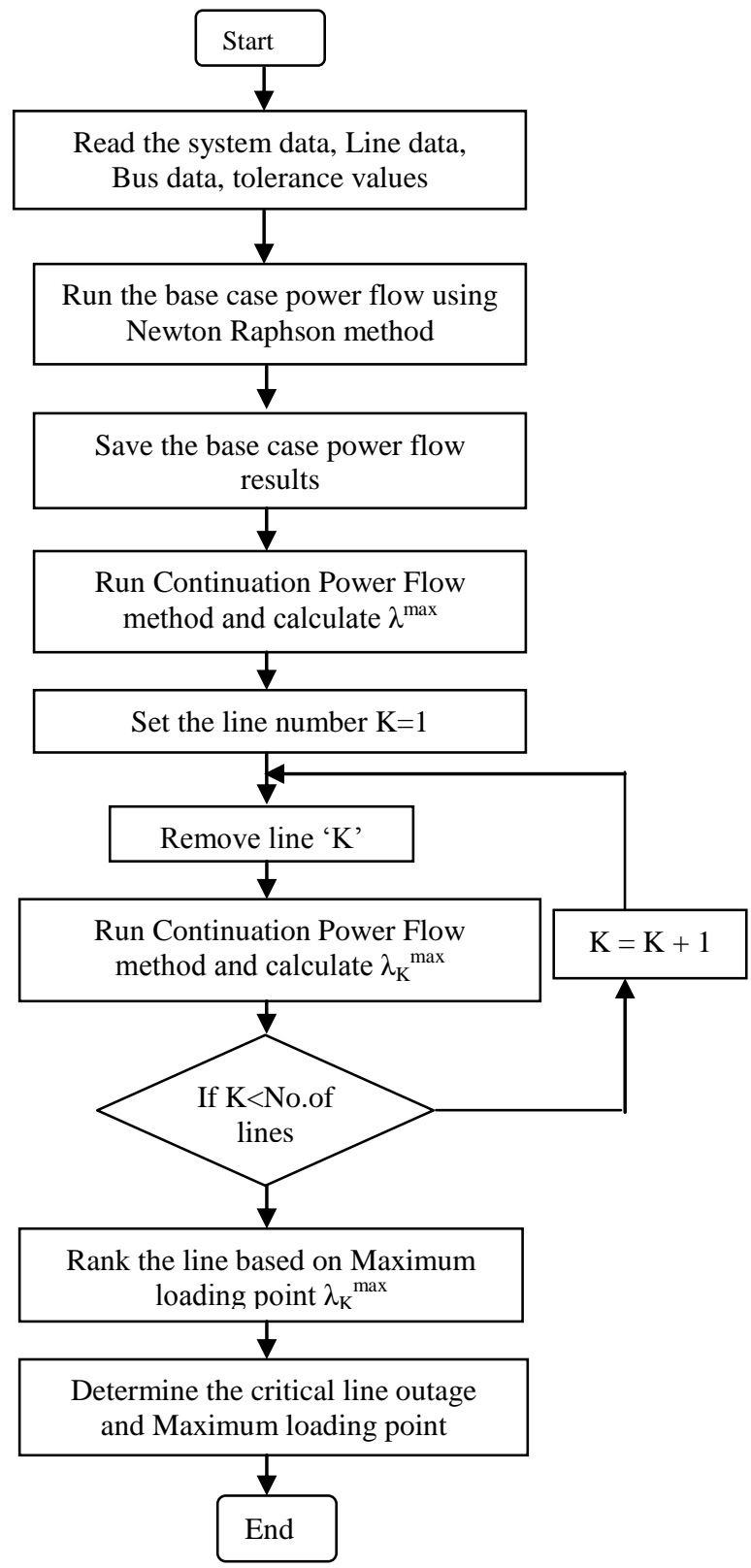

Fig. 1: Flow chart for contingency ranking 
The Maximum Loading Point and critical line are identified based on contingency ranking and CPF method. The flowchart for ranking of all possible contingencies is as shown in fig. 1. For normal and network contingencies, the MLP would be calculated by CPF method.

\section{TEST SYSTEM: CASE STUDY}

The proposed work is implemented on the IEEE 30 bus test system as shown in fig. 2 .

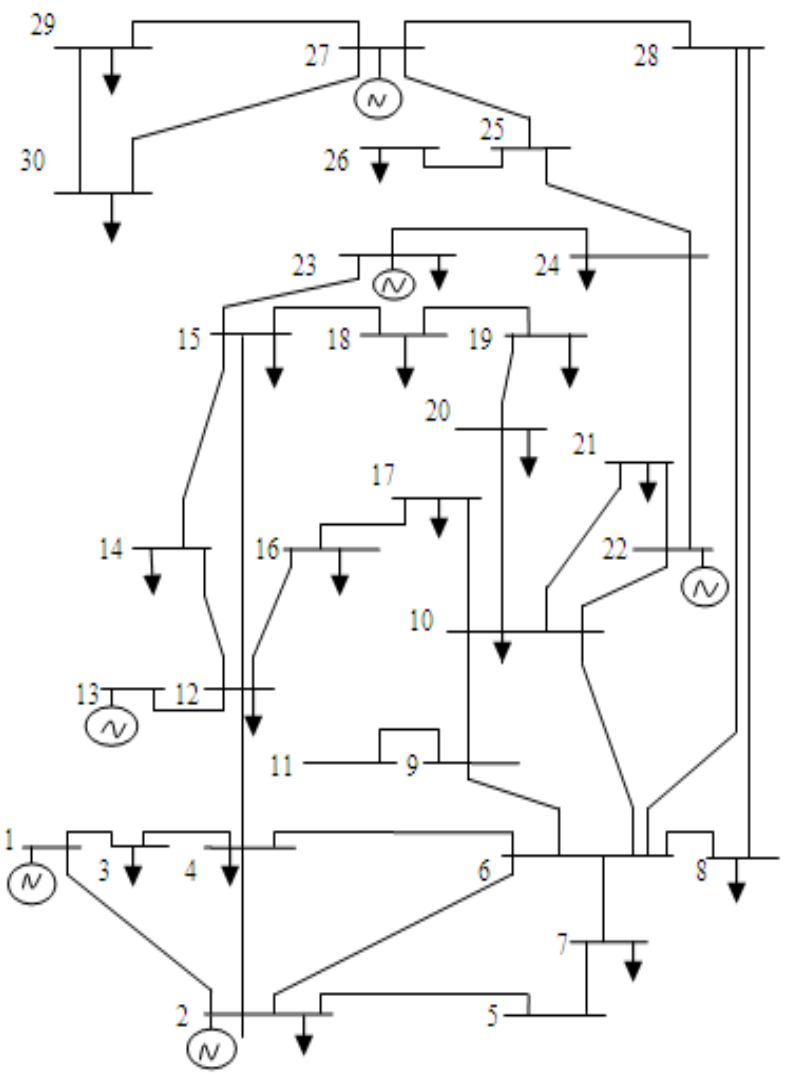

Fig. 2: IEEE 30 bus test system

\section{RESULTS AND DISCUSSIONS}

CPF method is used to analyse the MLP of power system with different operating conditions. To simulate the proposed methodology MATLAB software is used. Initially, base case load flow study is conducted for the IEEE 30 bus test system using Newton Raphson load flow method and corresponding voltage magnitudes are noted.

\section{Case 1: Without Line Outage Condition}

Now, the CPF method is applied for normal system without any contingency. The MLP is $\lambda=3.3069$. The critical bus is identified as bus 8 with voltage magnitude 0.961p.u.

\section{Case 2: With Line Outage Condition}

Then the CPF method is applied to the system with different line outage conditions. The results of single line outages are shown in table 1 . Here results of 20 single line outages are given using IEEE 30 bus test system.
TABLE I IEEE 30 bus system: Single line outage study

\begin{tabular}{|l|l|l|l|}
\hline $\begin{array}{l}\text { Line } \\
\text { outage }\end{array}$ & $\begin{array}{l}\text { Bus no. } \\
\text { with lowest } \\
\text { voltage }\end{array}$ & $\begin{array}{l}\text { Lowest voltage } \\
\text { in maximum } \\
\text { loading point }\end{array}$ & $\begin{array}{l}\text { Maximum } \\
\text { loading } \\
\text { point } \lambda_{\max }\end{array}$ \\
\hline 1. & 8 & 0.961 & 1.9855 \\
\hline 2. & 8 & 0.960 & 3.0360 \\
\hline 3. & 8 & 0.961 & 3.2978 \\
\hline 4. & 8 & 0.960 & 3.0685 \\
\hline 5. & 18 & 0.947 & 3.1529 \\
\hline 6. & 19 & 0.958 & 3.1447 \\
\hline 7. & 19 & 0.938 & 3.2199 \\
\hline 8. & 20 & 0.928 & 3.2344 \\
\hline 9. & 17 & 0.931 & 3.1458 \\
\hline 10. & 8 & 0.958 & 2.7033 \\
\hline 11. & 8 & 0.959 & 3.0196 \\
\hline 12. & 21 & 0.945 & 2.6023 \\
\hline 13. & 19 & 0.959 & 3.1592 \\
\hline 14. & 8 & 0.961 & 2.9807 \\
\hline 15. & 8 & 0.960 & 3.1929 \\
\hline 16. & 8 & 0.961 & 3.1219 \\
\hline 17. & 26 & 0.954 & 3.0966 \\
\hline 18. & 8 & 0.961 & 3.3069 \\
\hline 19. & 29 & 0.924 & 3.3056 \\
\hline 20. & 30 & 0.914 & 3.3052 \\
\hline & & & \\
\hline & 8 & \\
\hline
\end{tabular}

TABLE II Contingency ranking for single line outages

\begin{tabular}{|l|l|l|}
\hline Rank & $\begin{array}{l}\text { Line } \\
\text { outages }\end{array}$ & $\begin{array}{l}\text { Maximum } \\
\text { point } \lambda_{\max }\end{array}$ \\
\hline 1 & Line 1 & 1.9855 \\
\hline 2 & Line 29 & 2.6023 \\
\hline 3 & Line 27 & 2.7033 \\
\hline 4 & Line 31 & 2.9807 \\
\hline 5 & Line 28 & 3.0196 \\
\hline 6 & Line 19 & 3.0360 \\
\hline 7 & Line 21 & 3.0685 \\
\hline 8 & Line 35 & 3.0966 \\
\hline 9 & Line 33 & 3.1219 \\
\hline 10 & Line 23 & 3.1447 \\
\hline 11 & Line 26 & 3.1458 \\
\hline 12 & Line 22 & 3.1529 \\
\hline 13 & Line 30 & 3.1592 \\
\hline 14 & Line 32 & 3.1929 \\
\hline 15 & Line 24 & 3.2199 \\
\hline 16 & Line 25 & 3.2344 \\
\hline 17 & Line 20 & 3.2978 \\
\hline 18 & Line 38 & 3.3052 \\
\hline 19 & Line 37 & 3.3056 \\
\hline 20 & Line 36 & 3.3069 \\
\hline & & \\
\hline
\end{tabular}

It is observed that bus 8 is identified as weakest bus in the case of without contingency, but weakest bus position is changed during the line outage condition. The bus 8 is identified as weakest bus during the outage of line 1 connected between bus 1 and 2 .

Table. 3 shows contingencies ranking of line contingency ranking for single line outages. It is observed that outages of line 1, 29, $27 \& 31$ are considered as critical lines and have the higher ranks. The outage of line 1 with $\lambda_{\text {,max }}=$ 
1.9855 p.u. Hence, outage of line 1 is identified as the lowest MLP. The system voltage collapse and unwanted most critical line outage among the other line outages. So power system blackouts can be avoided by identifying its outage results in sudden voltage drop and leads to voltage collapse.

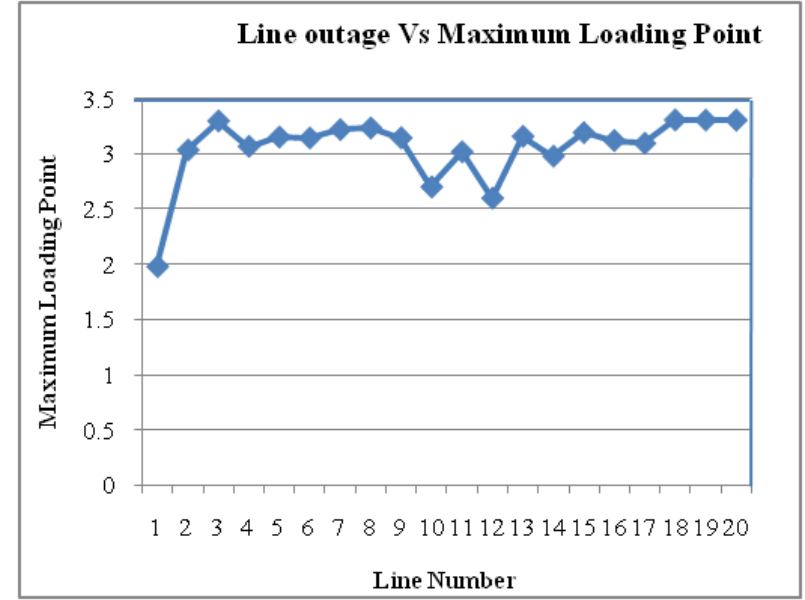

Fig. 3: Line outage Vs. Maximum Loading Point

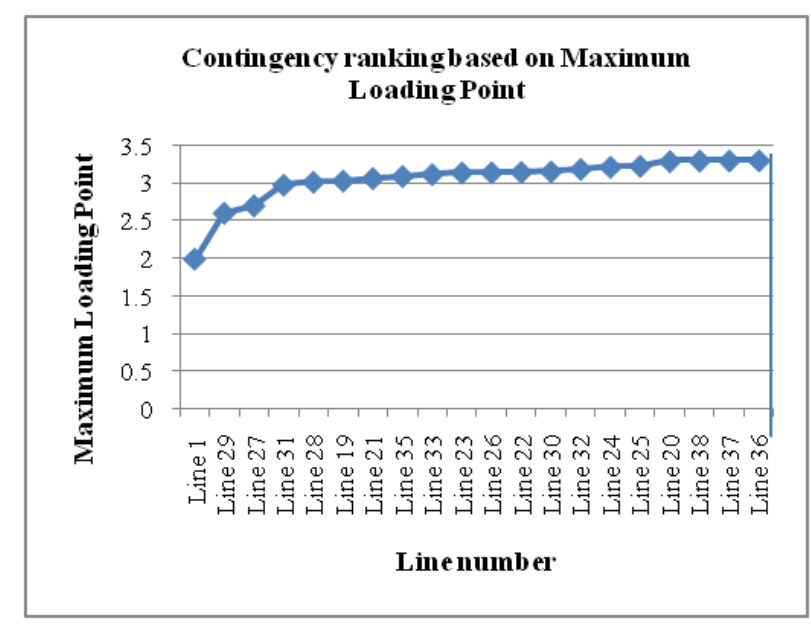

Fig. 4: Contingency ranking based on Maximum Loading Point

The fig. 3 shows the graph between each line outage and corresponding MLP. It is observed from the graph, the MLP has the lowest value during the outage of line1. The fig. 4 shows the contingency ranking of line outage based on the MLP. It is observed from the graph, Line outage 1 has the lowest MLP. Hence from these graphs, It is identified that the outage of line 1 is the most critical line outage compared to the other line outage conditions.

\section{CONCLUSION}

In this paper, CPF method is used to identify the MLP during normal and line outage conditions. The contingency analysis and ranking is done using $\mathrm{CPF}$ method based on the MLP for different line outage conditions. It is observed from the results that, the sudden line outages in the power system results in increasing voltage drop in some of the buses, the possibility of change in the weakest bus position and change in MLP. The critical line is identified as the outage line with the highest rank in the contingency ranking and with the these critical line outages with immediate necessary actions.

\section{REFERENCES}

[1] Mostafa Alinezhad and Mehrdad Ahmadi Kamarposhti " Static Voltage Stability Assessment Considering the Power System Contingencies using Continuation Power Flow Method", International Journal of Electrical and Electronics Engineering 4:5 2010

[2] Mehrdad Ahmadi Kamarposhti and Babak Mozafari "Study the Effects of power plant unit outages on Maximum Loading in Power System", Journal of Basic and Applied Scientific Reasearch, 1(11) pp. 2410-2416,2011.

[3] Nwohu, Mark Ndubuka, “ Estimation of bifurcation point in multibus system using generator reactive power limit approach", Journal of Electrical and Electronics Engineering Reasearch Vol,2(2),pp. 048-056, March 2010.

[4] Shobha Shankar, T. Ananthapadmanabha, "Fuzzy Approach to Critical Bus Ranking Under Normal and Line Outage Contingencies" , International Journal on soft computing Vol.2, no.1, pp 59-69, Feb2011.

[5] I Musirin, T.K. Abdul Rahman, "Estimating maximum loadability for Weak bus identification using FVSI.” IEEE power engineering review, 22:50-52,(Nov. 2002)

[6] Srivastava L., S.N. Singh, and J Sharma, "Knowledge Based Neural Network for Voltage Contingency Selection and Ranking”, IEEE Proceedings on Generation, Transmission and Distribution, 146(6) : 649-656 (Nov.1999)

[7] D.Hazarika, "A Fast Continuation Load Flow Analysis for an Interconnected Power System", International Journal of Energy Engineering, Nov 2012, Vol.2 Iss 4, pp. 126-136. 